\title{
Bioefficiency of Chromolaena odorata (Linn.) on hematological and lipid profiles in sublethal cyanide poisoning in male wistar rats
}

\section{Adeola. Folashade Ehigie}

Department of Biochemistry, College of Health Sciences, Ladoke Akintola University of Technology, Ogbomoso, Nigeria

Gbadebo Emmanuel Adeleke*

Department of Biochemistry, College of Health Sciences, Ladoke Akintola University of Technology, Ogbomoso, Nigeria

Fiyinfoluwa. D. Ojeniyi

Department of Biochemistry, College of Health Sciences, Ladoke Akintola University of Technology, Ogbomoso, Nigeria

Ona. Leonard Ehigie*

Department of Biochemistry, College of Health Sciences, Ladoke Akintola University of Technology, Ogbomoso, Nigeria

*Corresponding authors. E- mail: lehigie@lautech.edu.ng; geadeleke@lautech.edu.ng

\begin{abstract}
Chromolaena odorata is an invasive plant which is acclaimed to have cyanide remediation potential from contaminated sites. This examination means to decide the impact of ethanol concentrates of $C$. odorata (ECO), sodium thiosulphate and a mix of both on hematological parameters and blood lipid profile of rodents presented to potassium cyanide. $(\mathrm{KCN})$. A sum of thirty five male Wistar rats partitioned into seven groups of five units were used. KCN Group rats were administered with $\mathrm{KCN}$ alone. Rats in 100ECO, 150ECO, 200ECO groups were administered with 100,150 and $200 \mathrm{mg} / \mathrm{kg}$ body weight of ECO respectively. Rats under $\mathrm{Na}_{2} \mathrm{SS}_{2} \mathrm{O}_{3}$ and $\mathrm{Na}_{2} \mathrm{~S}_{2} \mathrm{O}_{3}+\mathrm{ECO}$ groups were administered $200 \mathrm{mg} / \mathrm{kg}$ sodium thiosulphate and sodium thiosulphate with $\mathrm{ECO}$ at $200 \mathrm{mg} / \mathrm{kg}$ respectively. The trial was done in about a month. Toward the finish of the investigation, the packed cell volume (PCV), hemoglobin level $(\mathrm{Hb})$, Red blood cells (RBC) and white blood cells (WBC) were resolved utilizing known biochemical methodology. The outcomes demonstrated a noteworthy increment $(p<0.05)$ in PCV, Hb, RBC and WBC level of remedial groups when contrasted with the cyanide group. Total cholesterol (TC), and triglyceride (TG) were altogether lower while HDL-cholesterol was fundamentally expanded in all the treated groups when contrasted and the untreated group given cyanide alone. However, no significant difference in LDL-cholesterol was indicated in all therapeutic groups compared with the cyanide group. The study revealed that $C$. odorata at the tested doses was able to improve the hematological parameters and lipid profile in cyanide exposed rats.
\end{abstract}

Keywords: Cyanide, Hematology, Lipid profile, Rats, Chromolaena odorata

\section{Article Info}

https://doi.org/

10.31018/jans.v12i1.2215

Received: January 6, 2020

Revised: January 29, 2020

Accepted: February 4, 2020

\section{How to Cite}

Ehigie, A. F. et al. (2020) Bioefficiency of Chromolaena odorata (Linn.) on hematological and lipid profiles in sublethal cyanide poisoning in male wistar rats. Journal of Applied and Natural Science, 12(1): 13 - 18 https://doi.org/

10.31018/jans.v12i1.2215

\section{INTRODUCTION}

Cyanide is a ubiquitous compound that appears in industrial waste. As anyone might expect, cyanide is appraised as one of top contaminants on the on the priority list of hazardous contaminants. Cyanide in the ecosystem can exist as free cyanide however is commonly found as metal complexes. A few cases show that it is profoundly conceivable to utilize plants for remediation of cyanide in aquatic environments and screen appropriate species suited to environmental conditions (Hidayati et al., 2009).

The mechanism by which cyanide inhibits cyto- chrome oxidase, leading to interference with the oxidative phosphorylation and tissue utilization of oxygen has been studied for several years. Theoretically, it is obvious that inhibition of cytochrome oxidase causes in vivo defect in global oxygen consumption resulting to cardiovascular system collapse (Julius et al., 2007). Among the pathophysiological anomalies associated with cyanide poisoning are hematologic and lipid profile abnormalities (Kadiri, 2017).

Treatment of cyanide harming depends on manufactured and substance specialists which by and large have such a significant number of reactions 
(Bhattacharya and Tulsawani, 2009). It is essential to deliberately survey the impacts of sub deadly portions of cyanide just as to distinguish appropriate mixes with potential for securing against weighty tissue impacts (Kadiri, 2017). The commonly available antidotes such as sodium nitrite, 4 -dimethyl aminophenol, sodium thiosulphate etc., have limitations that prompt novel research for improved treatment (Bhattacharya and Tulsawani, 2009; Baskin et al., 1999). Due to serious problems occurring from chronic ingestion of low amounts of cyanide, it is vital to carefully examine the effects of sub lethal doses of cyanide as well as to identify suitable compounds with potential for protecting against resultant tissue damages (Kadiri, 2017).

Blood is a good indicator of health and pathological reflector of the mirror of the entire body (Olusola et al., 2015). Cellular components of blood are useful in the evaluation of immunotoxic potential of a substance. Therefore, haematological indices are important in determining the body's functional status as a result of exposure to toxicants (Joshi et al., 2002). Hematological parameters are useful indices for the assessment of toxic potentials of substances in living systems. They are useful in explaining blood related functions of toxic substances. These types of laboratory investigations have several merits including high sensitivity, accuracy, and reliability and it remains the fundamental of ethical and rational research, disease diagnosis, prevention and treatment (Sunmonu and Oloyede, 2010). In the blood, the majority of cyanide absorbed is sequestered in the erythrocytes, and a relatively small proportion is transported through blood plasma to target tissues. This high concentration is not compensated for by the low activity of rhodanese although it is widely distributed throughout the body (Aminlari et al., 1997), thus increasing the sensitivity of blood tissue to toxicity of cyanide.

Hematological parameters are the significant markers for proposing adjusted inside and/or outer condition of creatures and varieties in these indices inside an individual can bring about inappropriate reactions to substance stressors. Presentation to toxins is thought to adjust hematological levels (Kadiri, 2017) often foreseeing the endurance of the uncovered creature. Subsequently, in the assessment of wellbeing conditions and result from the cyanide incited poisonous quality in life forms, parameters under hematological viewpoints are practiced as markers.

Cromolaena odorata has been widely known among the rural population of Nigeria as 'ewe Akintola'. It has been effectively used as a therapy against diarrhoea, malaria fever, tooth ache, diabetes, skin diseases, dysentery and colitis (Akinmoladun and Akinloye, 2007; Odugbemi, 2006). The plant has been employed in the reme- diation of cyanide from contaminated sites. Cyanide remediation capability of plants has been proposed to be given by their capacity to produce cyanogenic glucosides that promptly decompose to cyanide when the plant tissue is harmed. Since cyanide is a characteristic part of these plants, they have upgraded capacities with respect to metabolising cyanide.

So, the present study was undertaken to assess the biocompatibility of $C$. odorata in the aspect of heamatological profile of cyanide poisoned rats treated with the ethanol extracts of $C$. odorata (ECO) with the end goal of making these intrusive weed progressively valuable to man and to adding to the few literature accessible on the plants.

\section{MATERIALS AND METHODS}

Plant materials (Collection and preparation): Stem with leaves of $C$. odorata were collected in July in the year 2019, from an uncultivated land near a residential location at Hamama area, Ogbomoso, South-Western Nigeria and identified by Prof. A.T.J Ogunkunle at the Herbarium of Ladoke Akintola University of Technology (LAUTECH), Ogbomoso with voucher number, LHO 526. They were air dried, gathered in paper sacks and stored. The dried leaves were pummeled and 196 $\mathrm{g}$ of the pounded sample was extracted with 500 $\mathrm{ml}$ of $80 \%$ ethanol by maceration for $72 \mathrm{~h}$. The ethanol extract was concentrated in a rotary evaporator, lyophilized and from there on safeguarded for utilization.

Animals: Thirty-five (35) male Wistar albino rats weighing between $100 \mathrm{~g}$ and $150 \mathrm{~g}$ were distributed randomly into 7 groups (six (6) experimental groups and One (1) control group). The animals, which were from the same litter, were purchased from a local breeder in Ogbomoso and acclimatized for two weeks. They were fed on commercial rat pellets and water ad- libitum. They were kept in cages whose dimensions are $30 \mathrm{~cm}$ by $15 \mathrm{~cm}$ by $25 \mathrm{~cm}$ at room temperature. The study was conducted at the Animal House in the department of Biochemistry, Ladoke Akintola University of Technology, Ogbomoso, Oyo State, Nigeria. The animal experimental procedures were conducted in accordance with the National Institutes of Health guide for the care and use of laboratory animals (NIH Publications No. 8023) revised in 2002.

Hematological Studies: After a concise presentation of the rats to diethyl ether (analgesic) making the rats oblivious, the rats were set on a dissecting board with the appendages stuck to the board. The animals were analyzed beginning from the focal stomach locale upward to uncover the inward area and organs. Utilizing a syringe and needle, the blood was gathered from the core of each animal. $5 \mathrm{ml}$ of blood was collected into a tube containing Ethylene Diamine Tetra Acetate (EDTA) to determine hematological parameters 
Ehigie, A. F. et al. / J. Appl. \& Nat. Sci. 12(1): 13 - 18 (2020)

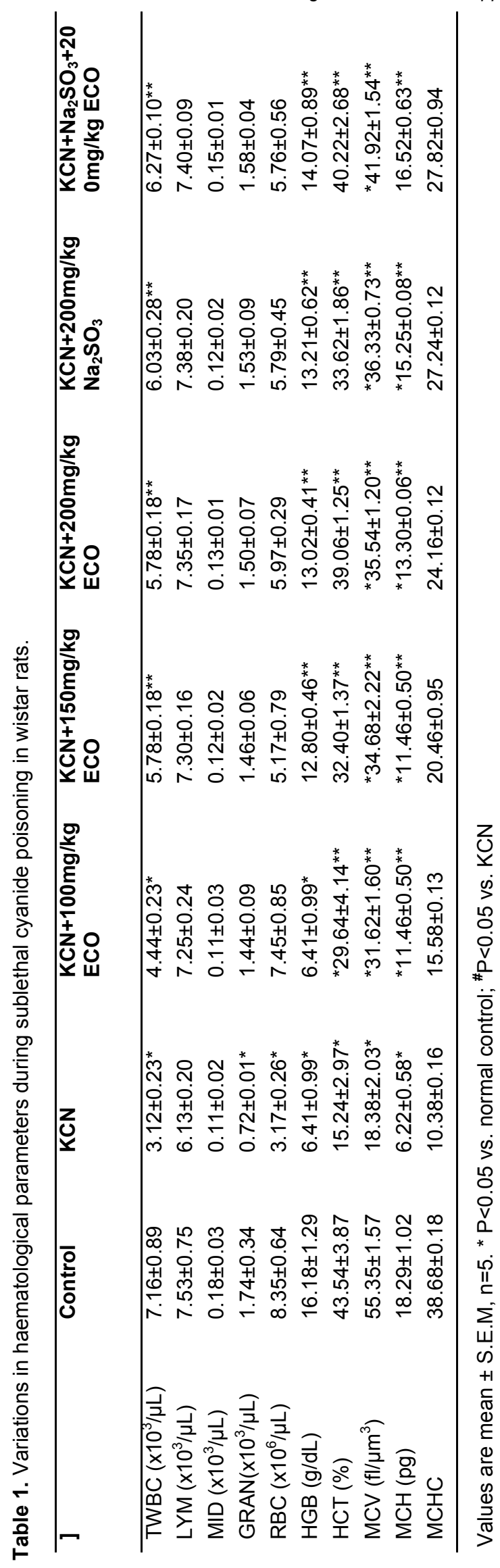

(Red blood count (RBC), Packed cell volumes (PCV), Hemoglobin ( $\mathrm{Hb})$ Concentrations, White blood cells (WBC) and differential counts, Mean corpuscular volume (MCV), Mean corpuscular hemoglobin $(\mathrm{MCH})$ and Mean corpuscular hemoglobin concentration (MCHC). Haematological examination was done following the International Council for Standardisation in Haematology (ICSH) standard procedures using Automated Hematology Analyzer-MC-2800 (Mindray Company, China).

Lipid profile studies: Total cholesterol, high density lipoprotein cholesterol (HDL-C), low density lipoprotein cholesterol (LDL-C), very low density lipoprotein cholesterol (VLDL-C) and triglycerides (TG) were evaluated utilizing commercial kits and adhering to standard strategies laid out by the maker, Randox Laboratories, UK.

Statistical analysis: All calculations were performed using SPSS/PC software. All results were analyzed using one way analysis of variance (ANOVA), trailed by Duncan's multiple comparisons test. The level of significance was set at $\mathrm{P}<0.05$.

\section{RESULTS}

The result of the effects of treatments on the haematological indices of rats is presented in Table 1. KCN-only group showed a significant decline $(\mathrm{P}<0.05)$ in total white blood cell count (TWBC) by $-56.42 \%(3.12 \pm 0.23)$ relative to control group (7.16 \pm 0.89 ). Other groups except $\mathrm{KCN}+100 \mathrm{mg} / \mathrm{kg}$ ECO group showed a significant increase in TWBC compared to KCN-only group. Administration of treatments advertised significant increase $(P<0.05)$ in the TWBC value of KCN group. Under the leucocyte differentials evaluated, only Granulocyes displayed a significant difference $(P<0.05)$ between KCN group and the control group. KCN reduces the Red blood cell count (RBC) by -62.03 $\%$. There was a gradual restoration of the red cell count by the test groups up to the group administered with $\mathrm{KCN}$ and combination of sodium thiosulphate and $200 \mathrm{mg} / \mathrm{kg}$ ECO. All groups except groups thiosulphate groups showed significant difference from the control value. Haemogobin result showed a significant decrease $(P<0.05)$ in rats exposed to $\mathrm{KCN}$ without treatment. The decrease was about $-60.38 \%$. The decline was circumvented by the therapeutic groups; $\mathrm{KCN}+100$ $\mathrm{mg} / \mathrm{kg}$ ECO (12.08 \pm 1.38$), \mathrm{KCN}+150 \mathrm{mg} / \mathrm{kg}$ ECO (12.80 \pm 0.46$), \mathrm{KCN}+200 \mathrm{mg} / \mathrm{kg}$ ECO (13.02 \pm 0.41$)$, $\mathrm{KCN}+200 \mathrm{mg} / \mathrm{kg} \quad \mathrm{Na}_{2} \mathrm{SO}_{3} \quad(13.21 \pm 0.62)$, $\mathrm{KCN}+\mathrm{Na}_{2} \mathrm{SO}_{3}+200 \mathrm{mg} / \mathrm{kg} \mathrm{ECO}(14.07 \pm 0.89)$. Under the haematocrit data, rats exposed to $\mathrm{KCN}$ only, displayed a significant decline of $-64.99 \%$ relative to the control value. There was a progressive increase in the haematocrit value in the extract treated groups up to the group administered $\mathrm{KCN}+200 \mathrm{mg} / \mathrm{kg}$ ECO. However, there was a 
Ehigie, A. F. et al. / J. Appl. \& Nat. Sci. 12(1): 13 - 18 (2020)

Table 2. Effects of treatments on lipid profile in rats dosed with sublethal dose of potassium cyanide.

\begin{tabular}{lllll}
\hline Parameters & Total cholesterol & Triglyceride & HDL-cholesterol & LDL-cholesterol \\
\hline Control & $94.77 \pm 7.61$ & $86.44 \pm 10.45$ & $65.56 \pm 1.17$ & $21.13 \pm 3.20$ \\
$\mathrm{KCN}$ & $188.85 \pm 2.69^{*}$ & $153.66 \pm 5.43^{*}$ & $37.71 \pm 1.23^{*}$ & $62.49 \pm 5.10^{*}$ \\
$\%$ Change $\dagger$ & $99.27 \%$ & $77.76 \%$ & $-42.48 \%$ & $195.74 \%$ \\
$\mathrm{KCN}+100 \mathrm{mg} / \mathrm{kg} \mathrm{ECO}$ & $107.64 \pm 4.07^{\#}$ & $104.06 \pm 6.34^{\#}$ & ${ }^{*} 55.57 \pm 1.91^{\#}$ & $40.80 \pm 5.10$ \\
$\% \mathrm{Change \dagger}$ & $13.58 \%$ & $20.38 \%$ & $-15.24 \%$ & $93.09 \%$ \\
$\mathrm{KCN}+150 \mathrm{mg} / \mathrm{kg} \mathrm{ECO}$ & $108.85 \pm 5.78^{\#}$ & $114.22 \pm 5.61^{\#}$ & ${ }^{*} 52.38 \pm 1.56^{\#}$ & $43.03 \pm 10.26$ \\
$\% \mathrm{Change \dagger}$ & $14.85 \%$ & $32.13 \%$ & $-20.10 \%$ & $103.64 \%$ \\
$\mathrm{KCN}+200 \mathrm{mg} / \mathrm{kg} \mathrm{ECO}$ & $110.64 \pm 7.75^{\#}$ & $102.06 \pm 3.33^{\#}$ & ${ }^{*} 52.09 \pm 1.91^{\#}$ & $50.63 \pm 6.10$ \\
$\% \mathrm{Change \dagger}$ & $16.75 \%$ & $18.07 \%$ & $-20.55 \%$ & $139.61 \%$ \\
$\mathrm{KCN}+200 \mathrm{mg} / \mathrm{kg} \mathrm{Na} \mathrm{SO}_{3}$ & $98.61 \pm 6.85^{\#}$ & $96.29 \pm 1.68^{\#}$ & $61.11 \pm 1.02^{\#}$ & $38.24 \pm 7.09$ \\
$\% \mathrm{Change \dagger}$ & $4.05 \%$ & $11.40 \%$ & $-6.79 \%$ & $80.97 \%$ \\
$\mathrm{KCN}+\mathrm{Na} \mathrm{SO}_{3}+200 \mathrm{mg} /$ & $95.61 \pm 6.85^{\#}$ & $90.29 \pm 1.68^{\#}$ & $63.11 \pm 1.02^{\#}$ & $35.24 \pm 7.09$ \\
$\mathrm{~kg} \mathrm{ECO}$ & & & & \\
$\% \mathrm{Change \dagger}$ & $0.89 \%$ & $4.45 \%$ & $-3.74 \%$ & $66.78 \%$ \\
\hline
\end{tabular}

Values are mean \pm S.E.M, $n=5 .{ }^{*} P<0.05$ vs. normal control; ${ }^{*} P<0.05$ vs. $K C N ; \dagger \%$ Change vs control

slight deviation at group 6 but there was resurgence in the group administered $\mathrm{KCN}+\mathrm{Na}_{2} \mathrm{SO}_{3}+200 \mathrm{mg} / \mathrm{kg} \mathrm{ECO}$ relative to $\mathrm{KCN}$ only group. Changes under mean corpuscular volume (MCV), mean corpuscular hemoglobin $(\mathrm{MCH})$ and mean cell hemoglobin concentration (MCHC) followed similar pattern. KCN significantly reduced the values under these indices while there was gradual increase in the values in all the therapeutic groups relative to $\mathrm{KCN}$ treated group. The results from Table 2 indicates that total cholesterol (TC), LDL-cholesterol and triglyceride (TG) was significantly lower in all the therapeutic groups when contrasted with the untreated group given cyanide alone. In any case, no noteworthy distinction in TC was shown in every one of the groups given diverse concentration of the extract (ECO), thiosulphate alone and thiosulphate combined with the extract when compared with the control group. Administration of potassium cyanide only significantly increased Total cholesterol level by $99.27 \%$. Relative to the control group, administration of 100,150 and $200 \mathrm{mg} / \mathrm{kg}$ body weight of $C$. odorata poisoned animals caused $13.58 \%, 14.85 \%, 16.75 \%$ surge in the level of Total cholesterol respectively while administration of thiosulphate alone and in combination with $C$. odorata displayed $4.05 \%, 0.89 \%$ increase respectively. Also no statistical difference in TG was also indicated in the groups given $100,200 \mathrm{mg} / \mathrm{kg}$ ECO, thiosulphate alone and thiosulphate combined with ECO with respect to the control. An essentially higher HDL-Cholesterol $(p<0.05)$ was anyway recorded in all the therapeutic groups when compared to cyanide alone whereas no significant difference was observed in the data of LDL-cholesterol relative to the group administered cyanide alone.

\section{DISCUSSION}

Alterations in haematological indices are considered to be among the major biomarkers of physio- logical stress (Akinrotimi et al., 2009). The present investigation indicated variations in haematological indices of rats exposed to sublethal dose ( $7 \mathrm{mg} / \mathrm{kg}$ body weight) of potassium cyanide (KCN) for 14 days. In this examination, the hematological profile following intoxication of animals with $\mathrm{KCN}$ uncovered a lessening in total white blood cell count (WBC) and differentials (Lymphocytes, monocytes and Granulocytes) levels which concurs with the discoveries of Kadiri, (2017). The leucopenia and neutropenia might be through the imperfections in the hemopoietic organs, for example, the spleen and bone marrow which is said to back off leucopoiesis (Anusuya, and Sumathi, 2015), while the lymphocytosis and monocytosis might be because of an expanded arrival of cells from lymphoid/myeloid tissues (Das and Mukherjee, 2003). Other hematological modifications watched ensuing to intoxication include diminished red blood cell count (RBC), Hemoglobin concentration (HB), percentage hematocrit, mean corpuscular volume (MCV), mean corpuscular hemoglobin $(\mathrm{MCH})$ and mean corpuscular hemoglobin concentration (MCHC) which concurs with the reports of Joshua and lyeopu, (2015). It was clarified by Dangana et al., (2010) that annihilation of RBCs and diminishing in $\mathrm{Hb}$ were liable for the abatement in $\mathrm{MCV}, \mathrm{MCH}$ and MCHC. Additionally, it has been clarified by Olusola et al., (2015), that hemophagocytosis and bone marrow concealment are basic components in producing hematological changes, for example, diminished PCV, $\mathrm{Hb}$, hematocrit, $\mathrm{MCV}, \mathrm{MCH}$ and $\mathrm{MCHC}$ and $\mathrm{RBC}$. In addition, Akinrotimi et al., (2009) revealed that a diminished level of $\mathrm{RBC}, \mathrm{Hb}$ and PCV were brought about by hindrance of hematopoiesis which prompted iron deficiency. Administration of C. odorata turned around these hematotoxicological impacts seen with cyanide inebriation. Ensuing to the treatment with $\mathrm{C}$. odorata and sodium thiosulphate either alone or in blend with C. odorata, there was a continuous improvement in WBCs, 
neutrophils, lymphocytes and monocytes, RBCs, $\mathrm{Hb}$, hematocrit, MCV, MCH and MCHC showing a reclamation to typical from the obsessive changes brought about by cyanide poisoning. Cyanide is metabolized in vivo by rhodanese (thiosulphate cyanide sulphurtransferase: EC 2.8.1.1) to a less toxic metabolite, thiocyanate, which is excreted in urine (Ehigie et al., 2015). Sulphur compounds with sulphane-sulphur modulate the activity of this enzyme thereby enhancing cyanide detoxification (Ojeniyi et al., 2019, Ehigie et al., 2019b, OlaMudathir and Maduagwu, 2015). The hematological changes observed may be due to efficient detoxification of cyanide which may be attributed to improved rhodanese activities in hematopoietic cells.

Cyanide intoxication significantly increases cholesterol, Triglyceride and LDL-cholesterol levels and decrease HDL cholesterol level when compared with the control group which is a strong indication of disturbances in cholesterol metabolism (Owoade et al., 2019). High levels of triglyceride and LDL-C has been associated with heart disease, diabetes and insulin resistance. The effects observed may be due to impairment of Liver function in the aspect of cholesterol and lipoprotein metabolism. The liver is known to have high activity of rhodanese due to its high exposure risk to blood cyanide (Aminlari et al., 1997). There seems to be a synergy between thiosulphate and Chromolaena odorata which is reflected in the better improvement of lipid profile. Thiosulphate has a role in enhancing rhodanese activity. The improvement in lipid profile may be a corollary of enhanced enzyme activity.

A significant correlation has been observed between rhodanese activity and the development of artherosclerosis (John, 1969). In fact, the study of Krueger et al., (2009) unveils low expression of rhodanese is associated with the development of artherosclerosis. That is, reduced activity of this enzyme, increases susceptibility to artherosclerosis. There was a reduction in cholesterol levels of rats co-administered with $\mathrm{KCN}$ and Chromolaena odorata extract when compared with $\mathrm{KCN}$ group only.

\section{Conclusion}

Cyanide introduction to the animals was found to adjust total $\mathrm{RBC}$ and $\mathrm{WBC}$ indices proposing anaemic condition and concealment of immune response respectively. The decrease level of $\mathrm{Hb}$ witnessed under current examination showed the conceivable outcomes of hypoxic states of exposed animals. Critical changes observed in heamatological and lipidemic records in a dynamic way recommends that i) $C$. odorata have a potential in turning around hematotoxicity and strange lipid profile intervened by cyanide, ii) the mix of $C$. odorata with sodium thosulphate have a synergis- tic impact in switching the hematological and lipidemic irregularities advertised by cyanide.

\section{REFERENCES}

1. Hidayati Nuril, Titi Juhaeti, Fauzia Syarif (2009).Mercury and Cyanide Contaminations in Gold mine environment and possible solution of cleaning up by using phytoextraction, HAYATI Journal of Biosciences, 16 (3): 88-94, 2009.

2. Julius Cuong Pham, David $T$ Huang, Francis $T$ McGeorge, and Emanuel P Rivers, "Clarification of cyanide's effect on oxygen transport characteristics in a canine model," 2007.

3. "Bhattacharya, R. and Tulsawani, R. (2009). Protective role of $\alpha$-ketoglutarate against massive doses of cyanide in rats. Environ. Biol. 30(4): 515-520."

4. Kadiri, H.E, "The Effects of Aqueous Vernonia Amygdalina (Bitter Leaf) Extract On The Lipid Profile And Some Hematological Parameters In Rats Exposed To Cyanide," 2017.

5. "Baskin, S.I., Porter, D.W., Rockwood, G.A., Romano, J.A., Patel, H.C., Kiser, R.C., Cook, C.M. and Ternay, A.L. (1999). In vitro and in vivo comparison of sulfur donors as antidotes to acute cyanide intoxication. J. Appl. Toxicol. 19: 173-183."

6. Olusola Ladokun, Matthew Ojezele, and Oluwatosin Arojojoye (2015), "Comparative study on the effects of aqueous extracts of viscum album (mistletoe) from three host plants on hematological parameters in albino rats,".

7. Joshi PK, Bose M, and Harish D., (2002). Haematological changes in the blood of Clarias battrachus exposed to mercuric chloride. Ecotoxicol Environ Monit., 12: 119-122

8. Sunmonu TO, Oloyede OB., (2010). Performance and haematological indices in rats exposed to monocrotophos contamination. Hum Exp Toxicol. 29 (10):845-850

9. Okonkwo JE, lyadi KC, Effiong CO., (2004). Effect of chronic administration of haematological parameters of rats. Nig J Physiol Sc., 19(1-2):10-13.

10.M. Aminlari, S. Gholami, T. Vaseghi, and A. Azarafrooz, (1997). Rhodanese (thiosulfate: cyanide sulfurtransferase) in the digestive tract of chicken at different stages of development, Poultry Science, 76 (2) $318-320$

11.Akinmoladun A C and Akinloye, (2007). Effect of Chromolaena odorata on hypercholesterolemia related metabolic imbalances. Proc. Akure-Humbold Kellog/3rd SAAT Annual Conference, FUTA, Nigeria, 287-290

12.Odugbemi T, (2006). Outlines and pictures of medicinal plants from Nigeria. University of Lagos Press, Lagos, Nigeria, Pp. 1-283

13.Akinrotimi OA, Abu OMG, Ansa EJ, Edun OM, George OS., (2009). Hematological responses of Tilapia guineensis to acute stress. Int. J. Nat. Appl Sci., 5:338-348.

14.Anusuya, B. and Sumathi, S. (2015). Haematological Alterations Due to Typhoid Fever in Mayiladuthurai Area, Nagapattinam. International Journal of Research in Pharmacology and Pharmacotherapeutics, 4: $210-216$

15.Das, B.K. and Mukherjee, S.C. (2003). Toxicity of Cypermethrin in Labeorohita Fingerlings: Biochemical Enzymatic and Haematological Consequence. 
Comparative Biochemistry and Physiology Part C: Pharmacology, 134: 109-121. https://doi.org/10.1016/ S1532-0456(02)00219-3

16. Joshua Charles Isirima, Iyeopu Minakiri Siminialayi, (2015). Effect of Chromolaena odorata Extracton Hematotoxicity and Spleen Histopathology Induced by Salmonella typhi in Wistar Rats

17.Dangana, A., Ajobiewe, J. and Nuhu, A. (2010). Hematological Changes Associated with Salmonella typhi and Salmonella paratyphi in Humans. International Journal of Biomedical Science, 6: 219-222

18.Ehigie O. L., Okonji R. E., Ehigie F. A., Olapeju A.O. and Fagbohunka B.S (2015). Purification and characterization of rhodanese from the leave of bitter melon (Momordica charantia). International Journal of Research in Applied, Natural and Social Sciences 3: 47-58

19.Ehigie Ona Leonard, Adeola Folashade Ehigie, Mohammed Adewumi Abdulrasak and Fiyinfoluwa D. Ojeniyi (2019). Kinetic properties of rhodanese from African locust bean seeds (Parkia Biglobosa). Asian Journal of Biomedical and Pharmaceutical Sciences, 9 ( 67): 18-23
20.Ola-Mudathir and Maduagwu, Emmanuel, (2015). Effects of Alium cepa Linn on rhodanese activities and half-life of cyanide in the blood. Int. J. Biol. Chem. Sci. 9(2): 1004-1012

21.Owoade O., A. Adetutu, S. O. Olorunnisola, and O. Ogundipe (2019). Investigation of Hepatoprotective and Antioxidant Activity of Celosia argentea against Tissue Injury Caused by Rifampicin Administration. Journal of Applied Life Sciences International 19(4): 1-11

22.John Esben Kirk, (1969). Enzymes of the Arterial Wall. Academic Press. ISBN: 978-1-4832-3177-8 DOI:10.1016/C2013-0-12424-5

23.Krueger, K. Koch, A. Jühling, M. Tepel, and A. Scholze, (2010). Low expression of thiosulfate sulfurtransferase (rhodanese) predicts mortality in hemodialysis patients," Clinical Biochemistry, 43 (1): 95 $-101$

24.Ojeniyi F.D., Ehigie A.F., Ehigie O.L., (2019) Evaluation of Enzymatic Changes in Sublethal Cyanide Poisoning in Wistar Rats Treated with Chromolaena odorata (Linn.) and Sodium Thiosulphate. J Plant Biochem Physiol. 7:242. DOI: 10.35248/23299029.19.7.242 